\title{
Pulmonary alveolar hemorrhage following thrombolytic therapy
}

This article was published in the following Dove Press journal:

International Medical Case Reports Journal

4 April 2017

Number of times this article has been viewed

\author{
Santhosh Narayanan' \\ NK Thulaseedharan' \\ Gomathy Subramaniam² \\ Geetha Panarkandy' \\ Narayanan Arathi' \\ 'Department of Medicine, \\ ${ }^{2}$ Department of Radiodiagnosis, \\ Government Medical College, \\ Kozhikode, Kerala, India
}

Correspondence: Santhosh Narayanan Department of Medicine, Government Medical College, Medical College PO, Kozhikode, Kerala 673008, India Email drsanthosh4@gmail.com

\begin{abstract}
We report a case of a 58-year-old male without any comorbidities who was thrombolysed with streptokinase for acute anterior wall myocardial infarction and developed massive hemoptysis with dyspnea and imaging features showing bilateral alveolar infiltrates. $\mathrm{He}$ was diagnosed with pulmonary alveolar hemorrhage and treated conservatively. His condition improved, and follow-up imaging showed resolution. Alveolar hemorrhage is a rare and lifethreatening complication of thrombolytic therapy.
\end{abstract}

Keywords: hemoptysis, alveolar hemorrhage

\section{Case report}

A 58-year-old male without any past history of comorbid illness or addictions presented to our emergency department with a history of left-sided constricting chest pain with excessive sweating for 1 hour duration. On examination, he was anxious with a pulse rate of $108 / \mathrm{min}$, regular in rhythm blood pressure (BP) of 120/80 $\mathrm{mmHg}$ and respiratory rate of $16 / \mathrm{min}$. Systemic examination was unremarkable. Electrocardiogram was suggestive of anterior wall myocardial infarction, with ST elevation in V1-V4 and ST depression in leads 1 and avL. Echocardiogram demonstrated regional wall motion abnormality in the anterior wall. He was initially loaded with aspirin and clopidogrel. He was thrombolysed with 1.5 million units of streptokinase. His chest pain subsided, and electrocardiogram taken 90 minutes after thrombolysis showed good ST resolution. After 6 hours, he developed massive hemoptysis and breathlessness. His oxygen saturation in room air fell to $86 \%$ from an initial value of $99 \%$. Examination revealed bilateral fine-end inspiratory crepitations in all lung fields. His jugular venous pressure was normal, and there were no signs of heart failure. A chest X-ray (Figure 1) revealed bilateral alveolar infiltrates. High-resolution computed tomography (HRCT) of thorax (Figure 2) confirmed the presence of alveolar hemorrhage. Hemoglobin fell from 14 to $10 \mathrm{~g} / \mathrm{dL}$. He had no other bleeding manifestations. He was treated with oxygen and blood transfusion. Diffusion lung capacity for carbon monoxide was markedly elevated. His condition improved symptomatically with treatment. After 1 week, his oxygen saturation in room air was $98 \%$ and his lung fields were normal on auscultation. A chest X-ray taken after 10 days showed resolution of lesions (Figure 3 ). The tests for anti-glomerular basement membrane antibodies, antinuclear antibodies, anti-doublestranded deoxyribonucleic acid antibodies, peripheral anti-neutrophil cytoplasmic antibodies (p-ANCAs) and cytoplasmic ANCAs showed negative results. Toxicology screening and retroviral screening were negative. On follow-up after 1 month, 


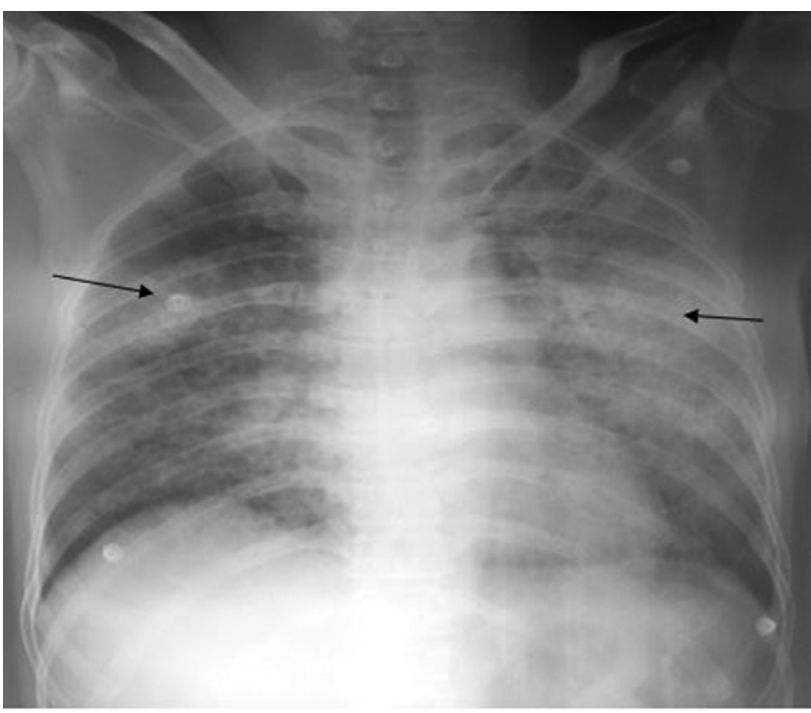

Figure I Chest X-ray postero-anterior view - bilateral alveolar infiltrates (arrow)

pulmonary function tests, including diffusion lung capacity for carbon monoxide, were done, which were reported as normal. He was restarted on clopidogrel after 3 months and is asymptomatic till date.

\section{Discussion}

Thrombolytic therapy for myocardial infarction can result in hemorrhagic complications, the most common being bleeding from vascular access sites. Pulmonary alveolar hemorrhage

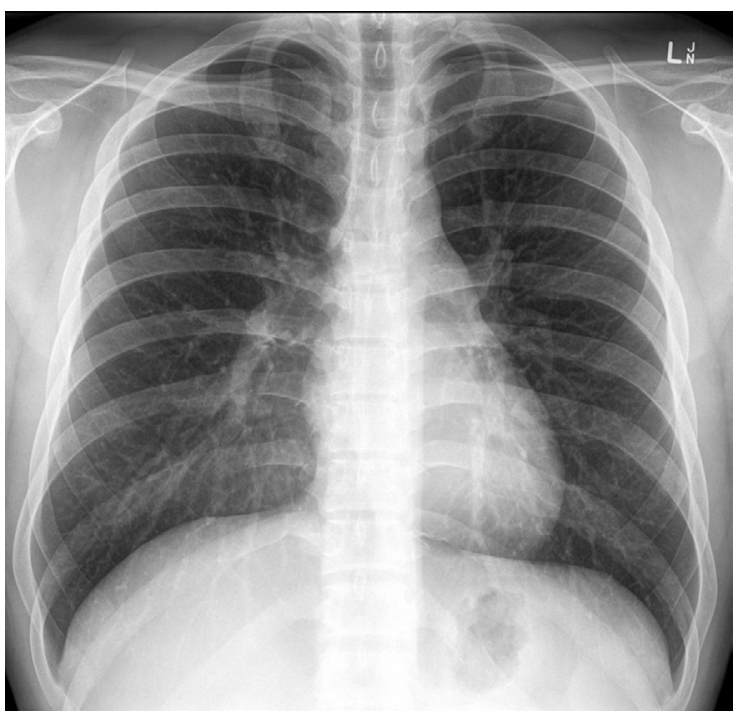

Figure 3 Resolution of lesions in chest X-ray (arrows).

is an uncommon and life-threatening complication of fibrinolytic therapy and should be considered as one of the differential diagnoses of pulmonary infiltrates or a decreasing level of hemoglobin after thrombolysis. ${ }^{1,2}$ There are no data regarding the exact incidence of this complication, except for a few case reports. It usually develops within a few hours to 5 days after thrombolysis. Some predisposing factors include immunodeficiency, pneumonia, chronic obstructive pulmonary disease, congestive heart failure and cocaine and tobacco

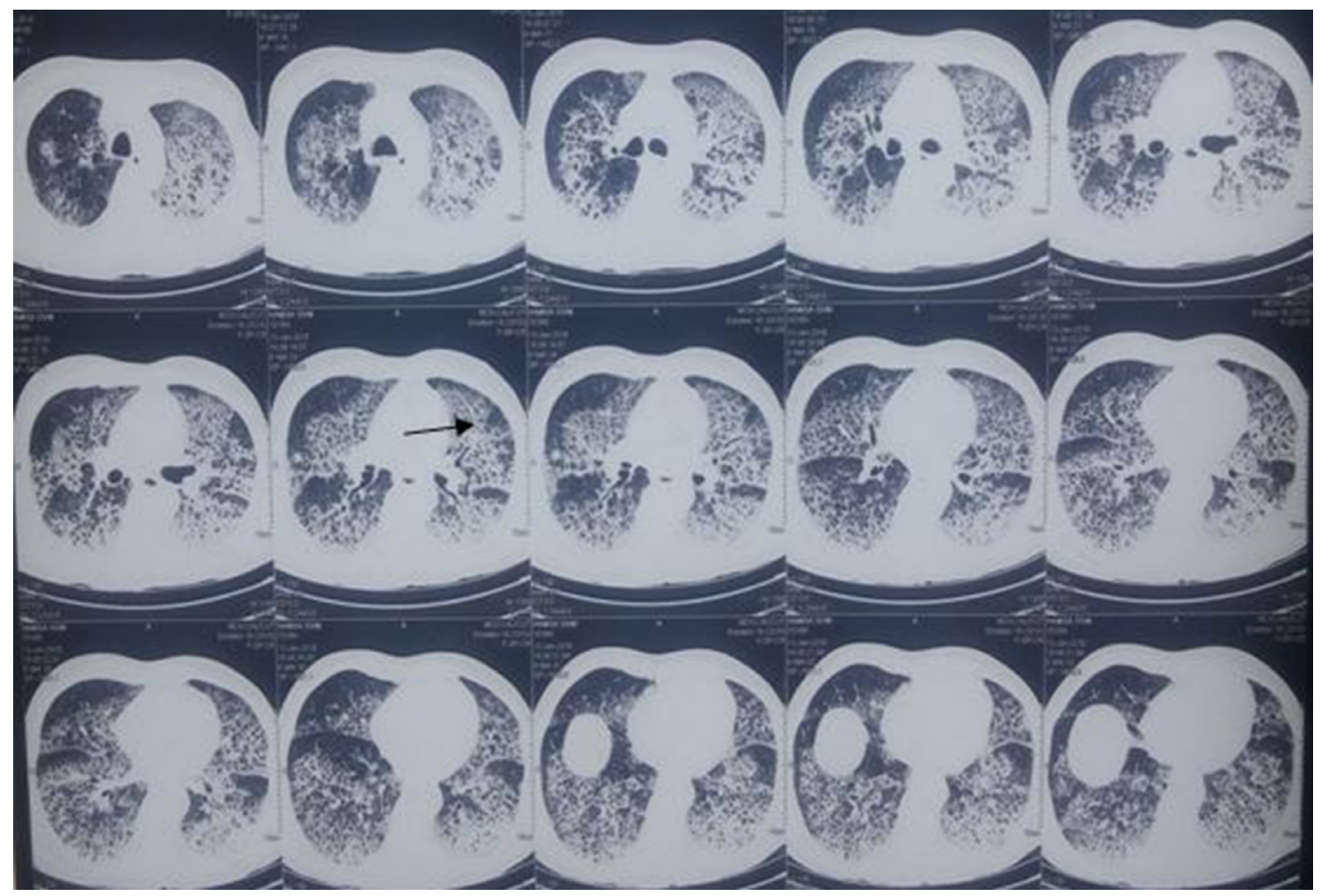

Figure 2 HRCT of thorax showing diffuse alveolar opacities scattered throughout lung fields (arrow).

Abbreviation: HRCT, high-resolution computed tomography. 
abuse. Pathogenesis of alveolar hemorrhage following thrombolysis is incompletely understood, and the exact mechanism is not yet elucidated. ${ }^{3,4}$ Other causes of pulmonary alveolar hemorrhage include acute respiratory distress syndrome, pulmonary renal syndrome, idiopathic pulmonary capillaritis and connective tissue diseases. ${ }^{5}$ Ikeda et $\mathrm{al}^{6}$ reported a case in which alveolar hemorrhage occurred following dual antiplatelet therapy. Clinically, pulmonary alveolar hemorrhage presents as a triad of hemoptysis, diffuse alveolar opacities in chest radiography and anemia. Many cases do not exhibit this classical triad, but alveolar hemorrhage should be suspected when at least two of them are present. Hemoptysis may not be evident in a few cases, because of the distal location of the bleeding source. ${ }^{7}$ Dyspnea results from both ventilation/ perfusion mismatch secondary to alveolar filling and anemia. Chest radiography usually shows bilateral symmetrical opacities and alveolar opacities. Rarely, there may be consolidation with air bronchogram or multiple nodules reflecting acinar filling. Pulmonary apices and costodiaphragmatic angles are spared. HRCT shows ground-glass opacities or consolidation, with predominantly central involvement and relative sparing of the lung periphery. ${ }^{8}$ At a later stage, alveolar opacities are replaced by more reticular opacities and micronodules, reflecting hemorrhage resorption in the pulmonary interstitium. An increase in diffusing capacity of the lung for carbon monoxide is attributed to increased carbon monoxide uptake by intraalveolar red blood cells. A macroscopically hemorrhagic bronchoalveolar lavage (BAL) fluid is considered diagnostic of acute alveolar hemorrhage. ${ }^{9}$ After a bleeding episode, hemoglobin is converted into hemosiderin by alveolar macrophages in 36-72 hours. Hemosiderin-laden macrophages reside in the lungs for 4-8 weeks. ${ }^{10}$ Management consists of treatment of respiratory failure with supplemental oxygen and mechanical ventilation, if needed. Instances with severe anemia due to rapid decline in hemoglobin should be corrected with packed cell transfusion. ${ }^{11}$

\section{Informed consent}

Written informed consent was obtained from the patient for the publication of this report and accompanying images.

\section{Disclosure}

The authors report no conflicts of interest in this work.

\section{References}

1. Levine MN, Goldhaber SZ, Califf RM, Gore JM, Hirsh J. Hemorrhagic complications of thrombolytic therapy in the treatment of myocardial infarction and venous thromboembolism. Chest. 1992;102(4 suppl): 364S-373S.

2. Disler LJ, Rosendorff A. Pulmonary hemorrhage following intravenous streptokinase for acute myocardial infarction. Int $J$ Cardiol. 1990;29(3):387-390.

3. Nathan PE, Torres AV, Smith AJ, Gagliardi AJ, Rapeport KB. Spontaneous pulmonary hemorrhage following coronary thrombolysis. Chest. 1992;101(4):1150-1152.

4. Gopalakrishnan D, Tioran T, Emanuel C, Clark VL. Diffuse pulmonary hemorrhage complicating thrombolytic therapy for acute myocardial infarction. Clin Cardiol. 1997;20(3):298-300.

5. Swanson GA, Kaeley G, Geraci SA. Diffuse pulmonary hemorrhage after streptokinase administration for acute myocardial infarction. Pharmacotherapy. 1997;17(2):390-394.

6. Ikeda M, Tanaka H, Sadamatsu K. Diffuse alveolar hemorrhage as a complication of dual antiplatelet therapy for acute coronary syndrome. Cardiovasc Revasc Med. 2011;12(6):407-411.

7. Ioachimescu OC, Stoller JK. Diffuse alveolar hemorrhage: diagnosing it and finding the cause. Cleve Clin J Med. 2008;75(4):264-265.

8. Picard C, Cadranel J, Porcher R, et al. Alveolar haemorrhage in the immunocompetent host: a scale for early diagnosis of an immune cause. Respiration. 2010;80(4):313-320.

9. Jin SM, Yim JJ, Yoo CG, et al. Aetiologies and outcomes of diffuse alveolar haemorrhage presenting as acute respiratory failure of uncertain cause. Respirology. 2009;14(2):290-294.

10. de Prost N, Parrot A, Picard C, et al. Diffuse alveolar haemorrhage: factors associated with in-hospital and long-term mortality. Eur Respir J. 2010;35(6):1303-1311.

11. Rabe C, Appenrodt B, Hoff C, et al. Severe respiratory failure due to diffuse alveolar hemorrhage: clinical characteristics and outcome of intensive care. J Crit Care. 2010;25(2):230-235.
International Medical Case Reports Journal

Publish your work in this journal

The International Medical Case Reports Journal is an international, peer-reviewed open-access journal publishing original case reports from all medical specialties. Previously unpublished medical posters are also accepted relating to any area of clinical or preclinical science. Submissions should not normally exceed 2,000 words or
Dovepress

4 published pages including figures, diagrams and references. The manuscript management system is completely online and includes a very quick and fair peer-review system, which is all easy to use. Visit http://www.dovepress.com/testimonials.php to read real quotes from published authors. 